\title{
Upaya Perbankan Syari’ah Dalam Perkuatan Permodalan Sektor Riil
}

\author{
Inne Risnaningsih ${ }^{1)}$ Heni Mulyasari ${ }^{2)}$ \\ Prodi Ekonomi Syariah Institut Manajemen Koperasi Indonesia \\ Prodi Ekonomi Syariah Universitas Muhammadiyah Bandung \\ inne_risnaningsih@yahoo.com \\ mulyasariheni@gmail.com
}

\begin{abstract}
ABSTRAK
Melihat fenomena saat ini tidak mengherankan apabila sejumlah pakar ekonomi terkemuka, mengkritik dan mencemaskan kemampuan ekonomi kapitalisme dalam mewujudkan kemakmuran ekonomi di muka bumi ini. Dalam teori ekonomi kapitalis (konvensional) mengemukakan pendekatan moneter baru yang entah disadari atau tidak, merupakan sudut pandang ekonomi Islam di bidang moneter, seperti peranan uang, bunga, dan kredit perbankan. Sedangkan nila-nilai negatif, paradigma konsep dan teori yang destruktif, filosofi materialisme, pengabaian moral dan banyak lagi konsep kapitalisme di bidang moneter dan ekonomi pembangunan perlu didekonstruksi. Sekarang tergantung kepada para akademisi dan praktisi ekonomi syari'ah untuk menyuguhkan konstruksi ekonomi syari'ah yang benarbenar adil, maslahah, dan dapat mewujudkan kesejahteraan umat manusia tanpa krisis finansial, stabilitas ekonomi tanpa penindasan, kezaliman dan penghisapan, baik antar individu dan perusahaan, Negara terhadap perusahaan maupun Negara kaya terhadap Negara miskin.
\end{abstract}

Kata kunci: Upaya Perbankan Syariah, Perkuatan Pembiayaan, Sektor Riil

\begin{abstract}
It is not surprising that a number of leading economists criticize and worry about the economic capacity of capitalism in realizing economic prosperity on this earth. In the capitalist (conventional) economic theory, a new monetary approach, whether consciously or not, is the point of view of Islamic economics in the monetary sector, such as the role of money, interest, and bank credit. Meanwhile, negative values, destructive concept and theory paradigms, materialism philosophy, moral neglect and many more concepts of capitalism in the monetary and economic development fields must be deconstructed. Now it is up to the academics and practitioners of sharia economics to present a sharia economic construction that is truly fair, maslahat, and can realize the welfare of mankind without financial crises, economic stability without oppression, injustice and exploitation, both between individuals and companies, the state against the company and the rich country against the poor country.
\end{abstract}

Keywords: Islamic Banking Efforts, Strengthening Financing, Real Sector 


\section{PENDAHULUAN}

Perekonomian saat ini digelembungkan oleh transaksi maya yang dilakukan oleh segelintir orang di beberapa kota di dunia, seperti London (27\%), Tokyo- Hongkong-china (25\%) dan Chicago-New York (17\%). Kekuatan pasar uang yang sangat besar dibandingkan kekuatan perekonomian dunia secara keseluruhan.Perekonomian global praktis ditentukan oleh pelaku lima Negara tersebut, karena itu Islam menolak keras segala jenis transaksi maya semacam itu yang terjadi di pasar uang saat ini sekali lagi ditegaskan "uang bukan komoditas". Praktek penggandaan uang dan spekulasi dilarang. Sebaliknya Islam mendorong globalisasi dalam arti mengembangkan perdagangan internasional.

Globalisasi dalam ekonomi Islam merupdari konsep universal Islam. Rosulullah telah menjadi pedagang internasional sejak usia remaja,ketika usia belasan tahun beliau telah berdagang ke negeri Syam (Suriah) Yaman dan beberapa Negara kawasan Teluk sekarang. Sejak awal kekuasannya, umat Islam menjalin kontak bisnis dengan Cina, India, Persia, dan Romawi, bahkan hanya dua abad kemudian (abad kedelapan), para pedagang Islam telah mencapai Eropa Utara. Ternyata nilai-nilai ekonomi syari'ah selalu aktual dan terbukti dapat menjadi solusi terhadap resesi perekonomian.

Menurut Agustianto (2008) di zaman nabi Muhammad saw jarang sekali resesi, zaman khalifah yang empat juga begitu, pernah sekali Nabi mengalami defisit yaitu sebelum Perang Humain, namun segera dilunasi setelah perang. Di zaman Umar bin Kottob (Khalifah ke dua) dan Utsman bin Affan (khalifah ketiga), malah APBN mengalami surplus, pernah dalam pemerintahan Khalifah Umar bin Abdul Aziz tak dijumpai satu orangpun yang miskin !! apa rahasianya?? Kebijakan moneter Rasulullah saw yang kemudian diikuti oleh para khalifah selalu diikuti dengan sektor Riil berupa perdagangan. Hasilnya pertumbuhan sekaligus stabilitas

Keterkaitan sektor moneter dan sektor riil merupakan obat mujarab untuk mengatasi gejolak mata uang. seperti yang melanda Indonesia pada tahun 1997 sampai saat ini. Perekonomian yang mengaitkan sektor keuangan langsung dan sektor riil akan membuat kurs mata uang stabil. Inilah yang dijalankan Bank-Bank Islam saat ini, dimana pembiayaan harus ada underline transaction nya. Tidak seperti bank konvensional yang menerapkan sistem ribawi.

Tantangan umat Islam dewasa ini, adalah menunjukkan keagungan dan keampuhan Ekonomi Syari'ah, tidak hanya.bagi masyarakat muslim melainkan juga bagi masyarakat non muslim, tidak hanya di Indonesia tetapi juga di dunia internasional. Islam ternyata mewariskan sistem perekonomian yang tepat, fair, manusiawi dan adil, untuk menciptakan kemaslahatan dan kesejahteraan hidup tidak hanya di dunia tetapi juga di akherat.

Berdasarkan fakta dan realita yang terjadi saat ini, jelas sekali bahwa drama krisis keuangan memasuki tingkat keterpurukan yang amat dalam. Hal tersebut dapat dikatakan bahwa krisis keuangan di Amerika jauh lebih parah daripada krisis keuangan di Asia pada tahun 1997-1998 yang lalu. Dampak krisis saat ini demikian terasa mengenaskan keuangan global. lagi pula sewaktu krisis moneter asia setidak nya ada "surga aman" atau safe heaven bagi para investor global yaitu Amerika Serikat, Eropa dan Jepang, tetapi kini semua pasar modal rontok dan semua investor panik. Karena itu seluruh pengamat ekonomi dunia sepakat bahwa guncangan ekonomi sebagai akibat badai keuangan yang melanda Amerika merupakan guncangan yang terparah setelah Great Depresion pada tahun 1930. 
Dari paparan di atas terlihat dengan nyata ,bahwa sistem perekonomian kapitalisme yang menganut laissez faire dan menganut sistem riba kembali tergugat faham neoliberalisme tidak bisa dipertahankan. Pemikiran Ibnu Taimiyah dan Ibnu Khaldun adalah suatu ijtihad yang benar dan adil untuk mensejahterakan, kemaslahatan ekonomi Masyarakat.

Melihat fenomena yang tragis tersebut, maka tidak mengherankan apabila sejumlah pakar ekonomi terkemuka, mengkritik dan mencemaskan kemampuan ekonomi kapitalisme dalam mewujudkan kemakmuran ekonomi di muka bumi ini. Bahkan cukup banyak klaim yang menyebutkan bahwa kapitalisme telah gagal sebagai sistem dan model ekonomi.

Kehadiran konsep ekonomi baru tersebut, bukanlah gagasan awam, tetapi mendapat dukungan dari ekonom terkemuka di dunia yang mendapat hadiah Nobel 1999, yaitu Joseph E. Stiglitz. Dia dan Bruce Greenwald menulis buku "Toward a New Paradigm in Monetary Economics". Mereka menawarkan paradigma baru dalam ekonomi moneter. Dalam buku tersebut mereka mengkritik teori ekonomi kapitalis (konvensional) dengan mengemukakan pendekatan moneter baru yang entah disadari atau tidak, merupakan sudut pandang ekonomi Islam di bidang moneter, seperti peranan uang, bunga, dan kredit perbankan (kaitan sektor riil dan moneter).

\section{PEMBAHASAN}

\section{Rekonstruksi Ekonomi Syari’ah Sebuah Keharusan}

Oleh karena kapitalisme telah gagal mewujudkan kesejahteraan yang berkeadikan, maka menjadi keniscayaan bagi umat manusia zaman sekarang untuk mendekonstruksi ekonomi kapitalisme dan merekonstruksi ekonomi berkeadilan dan berketuhanan yang disebut dengan ekonomi syari'ah. Dekonstruksi artinya meruntuhkan paradigma, sistem dan konstruksi materialisme kapitalisme, lalu menggantinya dengan sistem dan paradigm syari'ah. Capaiancapaian positif di bidang sains dan teknologi tetap ada yang bisa kita manfaatkan, artinya puing-puing keruntuhan tersebut ada yang bisa digunakan, seperti alat-alat analisis matematis dan ekonometrik, dsb. Sedangkan nila-nilai negative, paradigm konsep dan teori yang destruktif, filosofi materialism, pengabaian moral dan banyak lagi konsep kapitalisme di bidang moneter dan ekonomi pembangunan yang harus didekonstruksi. Karena tanpa upaya dekonstruksi, krisis demi krisis pasti terus terjadi, ketidakadilan ekonomi di dunia akan semakin merajalela, kesenjangan ekonomi makin menganga, kezaliman melalui sistem riba dan mata uang kertas semakin hegemonis.

Sekarang tergantung kepada para akademisi dan praktisi ekonomi syari'ah untuk menyuguhkan konstruksi ekonomi syari'ah yang benar-benar adil, maslahah, dan dapat mewujudkan kesejahteraan umat manusia tanpa krisis finansial, stabilitas ekonomi tanpa penindasan, kezaliman dan penghisapan, baik antar individu dan perusahaan, Negara terhadap perusahaan maupun Negara kaya terhadap Negara miskin.

\section{Hindari Maisir, Gharar dan Riba}

Ekonomi kapitalisme yang rawan krisis itu, tidak melarang praktik maghrib, sedangkan ekonomi Islam sangat keras mengecamnya. Maghrib adalah akronim dari maysir, gharar dan riba. Tiga macam praktik terlarang inilah yang menjadi faktor dan biang utama krisis. Maysir adalah kegiatan bisnis yang berbentuk judi dan spekulasi. Spekulasi selalu terjadi di pasar modal dalam bentk short selling dan margin trading. Sedangkan gharar ialah transaksi maya, 
drivatif dank arena itu ia menjadi bisnis resiko tinggi. Riba ialah pencarian keuntungan tanpa dilandasi kegiatan transaksi bisnis riil. Di pasar modal seringkali para investor meraup keuntungan tanpa adanya underlying asset, atau sektor riil yang melandasi. Tujuan investor bukan untuk menanam saham secara riil di sebuah emiten, tetapi semata untuk meraih gain melalui praktik margin trading. Selain itu harus diketahui bahwa di dalam financial market, margin trading dan fiat standart ditetapkan berdasarkan instrumen bunga.

Di pasar uang kegiatan transaksi spekulasi valas semacam transaksi swap, forward dan options selalu terjadi. Semua transaksi tersebut bertentangan dengan syari'ah, karena mengandung riba. Sementara itu, ekonomi syari'ah adalah ekonomi yang berusaha mendapatkan keseimbangan antara sektor keuangan dan sektor riil (atau biasa disebut economy 1 on 1). Artinya ekonomi yang mengaitkan secara ketat antara sektor moneter dan sektor reil. Tegasnya, one monetary unit for one real asset. Dalam kerangka itulah ekonomu Islam mengajarkan kegiatan bisnis riil melalui jual beli, bagi hasil dan ijarah.

Jantung dari sistem ekonomi kapitalisme adalah riba. Riba adalah puncak dari segala macam krisis. Artinya riba adalah biang utama terjadinya krisis. Kegiatan spekulasi dalam benuk margin trading dan short selling di pasar modal adalah riba, karena tanpa disadari oleh underlying transaction yang riil. Kegiatan transaksi derivative di bursa berjangka dan bursa komoditi semuanya adalah riba. Kegiatan spekulasi valas dengan motif untuk spekulasi, bukan untuk transaksi kegiatan ribawi. Sedangkan untuk jaga-jaga (precautionary) hukumnya makruh.

Ambilah 100-an buku-buku Islam (figh, tafsir dan hadits), lalu lihat dan analisis-lah definisi riba. Dari ratusan definisi riba itu disimpulkan bahwa riba ialah az-ziyadah lam yaqabilha 'iwadh, artinya riba adalah tambahan yang diperoleh tanpa didasarkan adanya 'iwadh. Iwad ialah transaksi bisnis riil yang terdiri dari 3 macam, yaitu jual beli, bagi hasil dan ijarah. Jual beli contohnya ialah seperti jual beli dengan segala macamnya (jual beli murabahah, salam, istisna), Transaksi bisnis riil juga dapat diwujudkan dengan bagi hasil dan ijarah. Bagi hasil diwujudkan dengan konsep mudharaah, syirkah, mudharabah, musytarakah, musyarakah mutanaqishah dan muzara'ah. Sedangkan ijarah diwujudkan dengan ijarah biasa, ijarah muwazy (parallel).

Transaksi mudharabah dan musyarakah serta transaksi jual beli murabahah, salam, istisna' dan ijarah (leasing), memastikan keterkaitan sektor moneter dan sektor riil. Oleh karena itu pula salah satu rukun jual beli ialah ada uang ada barang (ma'kud 'alaihi). Dengan demikian, future trading dan margin trading yang tidak diikuti dengan pengiriman barang adalah tidak sah. Jelasnya bahwa konsep ekonomi Islam menjaga keseimbangan sektor riil dan sektor moneter. Begitu pula dengan perbankan Islam yang pertumbuhan pembiayaannya tidak dapat terlepas dari pertumbuhan sektor riil yang dibiayainya.

Yang jelas tidak boleh ada tambahan (keuntungan) tanpa adanya transaksi bisnis riil. Seorang spekulan mata uang, yang meraup keuntungan dari selisih harga beli dollar dan jualnya adalah pelaku riba. Dalam ekonomi Islam, uang tidak boleh dijadikan sebagai komoditas sebagaimana yang banyak dipraktikan dewasa ini dalam kegiatan transaksi bisnis valuta asing. Menurut ekonomi Islam, transaksi valas hanya dibenarkan apabila digunakan untuk kebutuhan transaksi di sektor riil, seperti membeli barang untuk kebutuhan import, berbelanja atau membayar jasa di luar negeri dan sebagainya. Jual beli valas untuk kepentingan spekulatif menimbulkan dampak negative bagi perekonomian. 


\section{Eco-IQtishodi}

Jurnal Ilmiah Ekonomi dan Keuangan Syariah

Volume 2, Nomor 2, Januari 2021

E-ISSN: 2775-1457-- P-ISSN: 2685-2721

Dampak spekulasi valas ialah nilai suatu mata uang dapat berfluktiasi secara liar. Solusinya adalah mengatur sektor finansial agar menjauhi dari segala transaksi yang mengandung riba, seperti transaksi-transaksi maya di pasar uang. Mengambil gain dan keuntungan tanpa disadarkan pada kegiatan bisnis sektor riil adalah riba, baik di pasar uang maupun pasar modal. Maka, seorang spekulan saham di pasar modal juga telah melakukan praktik riba bahkan lebih jauh ia telah masuk kepada praktik gharar dan maysir. Demikian pula seorang yang ikut dalam transaksi bursa berjangka juga telah melakukan transaksi ribawi.

Karena ekonomi Islam tidak memisahkan sektor moneter dan sektor riil, maka jumlah uang yang beredar menurut Islam, ditentukan oleh banyaknya permintaan uang di sektor riil atau dengan kata lain, jumlah uang yang beredar sam banyaknya dengan nilai barang dan jasa dalam perekonomian. Demikian kata Ibnu Taymiyah di buku Majmu'Fatawa pada abad pertengahan Islam.

Dalam ekonomi Islam, sektor finansial mengikuti pertumbuhan sektor riil, inilah perbedaan konsep ekonomi Islam dengan ekonomi konvensional yaitu ekonomu konvensional jelas memisahkan antara sektor finansial dan sektor riil. Akibat pemisahan itu, ekonomi dunia rawan krisis, sebab pelaku ekonomi tidak lagi menggunakan uang untuk kepentingan sektor riil tetapi untuk kepentingan spekulasi mata uang. Spekulasi inilah yang dapat menggincang ekonomi berbagai Negara apalagi Negara yang kondisi politiknya tidak stabil.

Spekulasi mata uang yang menggangggu ekonomi dunia, umumnya dilakukan di pasarpasar uang. Pasar uang di dunia ini saat ini dikuasai oleh enam pusat keuangan dunia (London, New York, Chicago, Tokyo, Hongkong dan Singapura). Nilai mata uang Negara lain bisa saja tiba-tiba menguat atau sebaliknya. Lihat saja nasib rupiah semakin hari semakin merosot dan nilainya tidak menentu.

Di pasar uang tersebut, peran spekulan cukup signifikan untuk menggoncang ekonomi suatu Negara. Lihatlah Inggris, sebagai Negara yang kuat ekonominya, ternyata pernah sempoyongan gara-gara ulah spekulan di pasar uang, apalagi kondisinya seperti Indonesia, jelas menjadi bulan-bulanan para spekulan. Demikian pula ulah George Soros di Asia Tenggara tahun 1997.

Bagi spekulan, tidak penting apakah nilai menguat atau melemah. Bagi mereka yang penting adalah menciptakan mata uang selalu berfluktuasi. Tidak jarang mereka melakukan rekayasa untuk menciptakan fluktuasi bila ada momen yang tepat, biasanya satu peristiwa politik yang meimbulkan ketidakpastian.

Menjelang momentum tersebut, secara perlahan-lahan mereka membeli rupiah, sehingga permintaan akan rupiah meningkat. Ini akan mendorong nilai rupiah secara semu akan menjadi makanan empuk para spekulan. Bila momentumnya muncul dan ketidakpastian mulai merebak, mereka akan melapas secara sekaligus dalam jumlah besar. Pasar akan kebanjiran rupiah dan tentunya nilai rupiah akan anjlok. Para spekulan meraup keuntungan dari selisih harga beli dan harga jual. Makin besar selisihnya, makin menarik bagi para spekulan untuk bermain. 


\section{Kesadaran Ekonom dan Negara Maju}

Sebenarnya, sebagian pakar ekonomi dunia telah menyadari kerapuhan sistem moneter kapitalisme seperti itu. Teori bubble growth dan random walk telah memberikan penjelasan yang meyakinkan tentang bahaya transaksi maya (bisnis dan spekulasi mata uang dan bisnis spekulasi saham di pasar modal).

Pelarangan riba secara tegas terdapat dalam Al-Qur'an (QS 2 : 275-279), pada hakikatnya merupakan pelarangan terhadap transaksi maya atau derivative. Firman Allah, "Allah menghalalkan jual-beli (sektor riil) dan mengharamkan riba (transaksi maya)".

Dalam transaksi maya, tidak ada sektor riil (barang dan jasa) yang diperjualbelikan. Mereka hanya meperjualbelikan kertas berharga dan mata uang untuk tujuan spekulasi. Tambahan (gain) yang dperoleh dari jual beli itu termasuk kepada riba, karena gain itu diperoleh bighairi wadhin, yakni tanpa ada sektor riil yang dipertukarkan, kecuali mata uang itu sendiri.

Para pemimpn Negara G7 pun, telah menyadari bahaya dan keburukan transaksi maya dalam perekonomian. Pada tahun 1998 mereka menyepakati bahwa perlu adanya pengaturan di pasar uang sehingga tidak menimbulka krisis yang berkepanjangan. Jadi, bila Negaranegara G7 telah menyadari bahaya transaksi maya, menapa Indonesia masih elum melihat dampat negatifnya bagi perekonomian dan segera mendorong konsep dan blueprint ekonomi Islam.

Selanjutnya, untuk meminialisir kegiatan spekulasi dan bubble economy para ekonom barat mengusulkan untuk mengetatkan regulasi investasi. Ben Bernake, Chairman of Federal Reserve bahkan sampai meminta kepada kongres AS untuk menyetujui penambahan regulasi bagi bank investasi agar tidak terjadi spekulasi yang berlebihan di pasar asset keuangan. Pendapat senada juga diutarakan oleh Direktur IMF Strauss-Kahn mengenai perlunya penambahan aturan dan transparansi untuk menghindari krisis yang lebih parah. Meskipun kedua pernyataan ini terdengan berlawanan dengan semangat kapitalisme AS namun akhirnya sebagian ekonom dan pengamat pasar keuangan sepakat bahwa liberalisasi pasar keuangan cenderung mendorong kepada ketidakstabilan ekonomi.

\section{Upaya Bank Syari’ah menghidupkan Sektor Riil}

Bank syari'ah adalah suatu lembaga keuangan yang sangat peduli kepada pengembangan usaha sektor riil. Sektor riil adalah jati diri dan karakter utama bank syari'ah. Islam mewajibkan seluruh transaksi ekonomi dan keuangan didasarkan pada sektor riil seperti melalui jual beli, bagi hasil dan ijarah. Setiap keuntungan tanpa didasarkan pada sektor riil adalah riba. Riba adalah tambahan tanpa landasan transaksi bisnis riil.

Fakta menunjukan bahwa pertumbuhan dan perkembangan lemaga perbankan dan keuangan syari'ah mengalami kemajuan yang sangat pesat, baik di dunia internasional maupun di Indonesia. Konsep perbankan dan keuangan Islam yang pada mulanya di tahun 1970-an hanya merupakan diskusi teoritis, kini telah menjadi realitas factual yang mencengangkan banyak kalangan. Kini lembaga perbankan syari'ah telah merambah 75 negara, tidak hanya di Negara-negara muslim, tetapi juga negara-negara sekuler yang minoritas muslim seperti Denmark, Luxemburg, Inggris, Australia dan Amerika Serikat.

Di Indonesia, dalam empat tahun belakangan ini, pertumbuhan perbankan syari'ah ratarata mencapai $60 \%$ setahun. Hingga kini asset bank syari'ah telah mencapai lebih Rp. 47 
triliun dengan jaringan pelayanan mencapai 1440 kantor yang tersebar di seluruh Indonesia (Data Bank Indonesia, September 2008). Angka ini belum termasuk seribuan gerai Kantor POS yang dimiliki oleh Bank Muamalat.

\section{Prinsip Ekonomi Islam berbasis Sektor Riil}

Dalam ekonomi syari'ah, dikotomi sektor moneter dan riil tidak dikenal. Sektor moneter dalam definisi ekonomi Islam adalah mekanisme pembiayaan transaksi atau produksi di pasar riil, sehingga jika menggunakan istilah konvensional, maka karakteristik perekonomian Islam adalah perekonomian riil, khususnya perdagangan. Inilah yang dianjurkan Islam, "Allah menghalalkan jual beli (perdagangan) dan mengharamkan riba." (QS 2:275). Ayat tersebut secara tegas membolehkan jual-bali atau perdagangan dan mengharamkan riba. Jual beli atau perdagangan adalah kegiatan bisnis sektor riil. Kegiatan bisnis sektor keuangan tanpa dikaitkan dengan sektor riil adalah aktivitas ribawi yang dilarang dalam ekonomi Islam.

Oleh karena keharusa terkaitnya sektor moneter dan sektor riil, maka perbankan syari'ah mengembangkan sistem bagi hasil, jual beli dan sewa. Dalam bagi hasil, terdapat bisnis sektor riil yang dibiayai dengan pembagian keuntungan yang fluktiatif. Demikian pula dalam jual beli ada sektor riil yang mendasari kebolehan penambahan (ziyadah) dalam harta.

Dalam sektor ekonomi syari'ah sistem bagi hasil (profit dan loss sharing) yang kemudian menjadi jantung dari sektor "moneter" Islam, bukan bunga. Karea sesungguhnya, bagi hasil sebenarnya sesuai dengan iklim usaha yang memiliki kefitrahan uuntung atau rugi. Tidak seperti karakteristik bunga yang memaksa agar hasil usaha selalu positif. Islam tidak mengenal konsep prinsip keadilan tertap berjalan dalam perkonomian. Karena memang kestabilan ekonomi bersumber dari prinsip keadilan yang dipraktikan dalam perekonomian.

Ekonomi Islam bukan saja menjanjikan kestabilan "moneter" tetapi juga pembangunan sektor riil yang lebih kokoh. Krisis moneer yang telah menjadi krisis multidimensi di Indonesia ini, tak dapat diobati dengan variabel yang menjadi sumber krisis sebelumnya, yaitu sistem bungan dan utang, artinya tidak bisa dengan mengutak ngatik suku bunga tetapi harus oleh variabel yang jauh dari karakteristik itu, yaitu dengan sistem bagi hasil dalam dunia perbankan dan lembaga finansial lainnya.

Fatwa MUI tentang pelarangan bunga, dalam perspektif ekonomi adalah sebuah upaya untuk mengobati krisis yang melanda Indonesia sejak 10 tahun terakhir, karena kalau sistem bunga masih dipertahankan, seratusan triliyun yuang rakyat yang berasal dari pajak dan kenaikan harga BBM, listrik dan telepon digunakan untuk kepentingan membayar bunga yang disumbangkan untuk bank-bank rekayasa dalam bentuk bunga obligasi, bahkan dalam tiga tahun terakhir, lebih dari seratus triliyun disumbangkan untuk membayar bunga SBI yang saat itu pernah mencapai $17 \%$ setahun. Padahal dana sebesar itu bisa digunakan untuk pendidikan, pemberdayaan ekonomii rakyat dan kebutuhan infrastruktur seperti pembangunan jalan-jalan dan kebutuhan-kebutuhan lainnya. Karena itulah diusulkan kepada pemerintah agar mendorong mekanisme jual beli dan bagi hasil menjadi dominan dalam sektor keuangan Indonesia, melalui lembaga perbankan syari'ah agar sektor riil kembali bangkit di Indonesia.

Dalam ekonomi Islam, sektor finansial mengikuti pertumbuhan sektor riil. Inilah perbedaan konsep ekonomi Islam dengan ekonomi kapitalis. Di dalam ekonomi kapitalis dengan jelas dipisahkan sektor finansial dengan sektor riil. Maka pengembangan perbankan 
dan keuangan syari'ah saat ini sangat tepat dan wajib didukung semua pihak, baik pemerintah, ulama, ekonom, pengusaha dan seluruh lapisan masyarakat.

\section{KESIMPULAN}

Untuk menghidupkan sektor riil langkah-langka yang perlu diambil antara lain:

Pertama, seluruh masyarakat perlu disadarkan secara akal sehat dan rasional, bahwa sistem bunga (riba) sangat merusak perekonomian global dan regional karena itu, umat Islam wajib hijrah ke bank syari'ah dalam menaung dan mendepositokan uangnya. Tanpa dana masyarakat, maka pengembangan sektor usaha riil masyarakat akan lesu darah. Dana tabungan dan deposito atau giro rakyat adalah darah bagi sektor riil. Jika bank syari'ah semakin besar, maka permodalan untuk UKM makin besar sehingga manfaatnya untuk bangsa juga makin besar

Kedua, bank syari'ah yang selama ini sangat peduli pada Usaha Kecil Menengah (UKM), lebih meningkatkan perhatiannya pada sektor ini, karena jumlah UKM di Indonesia mencapai 40 juta jiwa. Jika sektor UKM ini dapat diberdayakan, maka kemiskinan Insya Allah dapat dientaskan secara signifikan karena 40 juta UKM terdiri lebih dari 120 juta jiwa, jika setiap keluarga UKM dikalikan 3 orang.

Keiga, mengingat bank syari'ah dihadapkan pada kendala popularitas yang masih kurang di kalangan masyarakat, maka cukup penting untuk ditingkatkan popularitasnya kepada para nasabah, melalui promosi, advokasi, dan bebagai jalur sosialisasi di berbagai lembagalembaga pendidikan, bekerja sama dengan pemerintah daerah dan perguruan tinggi, ulama dan ormas Islam dimana bank syari'ah beroperasi.

\section{DAFTAR PUSTAKA}

Al Quranul Karim

Agustianto,(2008),Memanfaatkan Krisis Keuangan Global untuk memperkuat sistem Ekonomi Syariah, Makalah yang disampaikan pada sosialisasi Perbankan Syariah,soluai perkuatan di pemkot Sukabumi

Ibnu Tayimiah ( 1900), Majmu Fattawa

Joseph E Stiglitz dan Bruce Greenwald (1999),Toward a New Paradigm in Monetary Economics 